\title{
Regionalização das vazões de permanência para as bacias hidrográficas do Estado de Sergipe segundo suas regiões climáticas
}

Regionalization of permanence flow for the basins in State of Sergipe according to their climatic regions

\author{
E. H. M. Schneider ${ }^{1 *}$; A. de G. Barbosa ${ }^{2}$; I. M. L. Rocha ${ }^{2}$; L. A. Mendes ${ }^{1,2}$ \\ ${ }^{1}$ Programa de Pós-Graduação em Engenharia Civil, Universidade Federal de Sergipe, 49100-000, São Cristóvão- \\ Sergipe, Brasil \\ ${ }^{2}$ Departamento de Engenharia Civil, Universidade Federal de Sergipe, 49100-000, São Cristóvão-Sergipe, Brasil
}

*erwinhenrique@gmail.com

(Recebido em 25 de maio de 2017; aceito em 28 de setembro de 2017)

\begin{abstract}
A estimativa da disponibilidade hídrica em uma bacia é uma das principais informações que alicerça a correta gestão dos recursos hídricos. Considerando-se a importância de se atender as regiões com ausência ou escassez de monitoramento fluviométrico, desenvolveu-se no presente estudo a construção de modelos matemáticos de regionalização de vazões para diversas bacias do Estado de Sergipe. Contudo, essa metodologia tem limitações quando os dados hidrométricos disponíveis são muito escassos ou quando a bacia possui grande variabilidade fisiográfica e climatológica, comprometendo a determinação da correta vazão disponível. O presente trabalho objetiva determinar a equação regionalizada $Q_{90}$ que melhor se ajuste ao comportamento hidrológico das bacias do Estado de Sergipe, considerando as diferentes regiões climáticas sergipanas - Tropical Úmida, Agreste e Semiárido -, de forma a se obter uma pequena variação entre a vazão real e a vazão calculada pela regionalização. Na determinação da vazão de permanência $\mathrm{Q}_{90}$, foi aplicado o Método Tradicional de regionalização, tendo como variáveis independentes a área de drenagem do posto fluviométrico e a sua precipitação média acumulada.

Palavras-chave: Gestão de Recursos Hídricos. Regionalização hidrológica. Climatologia
\end{abstract}

The estimation of the water availability in a basin is one of the main information that supports the correct management of the water resources. Considering the importance of attending to regions with absence or scarcity of fluviometric monitoring, in the present study the construction of mathematical models of flow regionalization for several basins in the State of Sergipe was developed. However, this methodology has limitations when the available hydrometric data are very scarce or when the basin has great physiographic and climatological variability, compromising the determination of the correct available flow. The present work aims to determine the regionalized equation $\mathrm{Q}_{90}$ that best adjusts to the hydrological behavior of the basins of the State of Sergipe, considering the different climatic regions of Sergipe - Tropical Humid, Agreste and Semiarid -, in order to obtain a small variation between the flow And the flow calculated by regionalization. In the determination of the $\mathrm{Q}_{90}$ permanence flow, the Traditional Method of regionalization was applied, having as independent variables the drainage area of the fluviometric station and its accumulated mean precipitation.

Keywords: Management of Water Resources. Hydrological regionalization. Climatology.

\section{INTRODUÇÃO}

Para que a gestão dos recursos hídricos ocorra de maneira adequada, requer-se que esta seja específica para cada região, levando em conta o conhecimento das diferentes componentes do ciclo hidrológico, notadamente da precipitação - principal entrada de água na bacia hidrográfica - e da vazão - possibilita a convivência harmoniosa entre os múltiplos usos dos recursos hídricos e auxilia nos processos de outorgado direito de uso da água e cobrança pelo uso desta.

Infelizmente a rede hidrométrica não cobre completamente toda a hidrografia, deixando trechos bastante extensos sem os dados necessários à estimativa dessas vazões e controle da precipitação. Uma técnica utilizada para estimar parâmetros hidrológicos em locais sem dados ou em quantidade 
insuficiente é a regionalização de vazões [1], que consiste num conjunto de ferramentas que exploram ao máximo os dados disponíveis de forma a determinar a vazão em um ponto de interesse por meio de um processo de transferência de informações de um local para outro de comportamento hidrológico semelhante. Assim, a técnica da regionalização de vazões já foi utilizada no cálculo dos deflúvios em diferentes bacias e com diferentes aplicações [2-8].

A gestão, o planejamento, o desenvolvimento de projetos e a operação de qualquer obra relacionada ao aproveitamento dos recursos hídricos em uma bacia hidrográfica baseiam-se na avaliação da demanda frente à disponibilidade de água na bacia. A demanda pode ser estimada a partir de um eficiente cadastramento de usuários, dinâmico e contínuo no tempo. Por sua vez, a disponibilidade hídrica na seção fluvial de interesse varia no tempo e no espaço e pode ser estimada por meio da avaliação do regime hidrológico da bacia, a partir de dados fluviométricos ou de estudos que utilizem modelos como os de regionalização, por exemplo.

Em Sergipe, a Secretaria de Estado do Meio Ambiente e Recursos Hídricos (SEMARH) adota a vazão com permanência de $90 \%$ no tempo $\left(\mathrm{Q}_{90}\right)$ como referência para cálculo da disponibilidade de hídrica para concessão de outorga de direito de uso da água [9]. Uma vez que a densidade de postos fluviométricos no Estado é baixa, mostra-se útil o emprego de equações regionalizadas para estimar a disponibilidade hídrica em cada seção dos corpos d'água. Além disso, uma vez que a distribuição das precipitações é desigual não apenas entre as regiões do Estado como também ao longo do ano, a técnica da regionalização também pode ser empregada para obtenção de equações que permitam estimar a disponibilidade hídrica em cada mês ou período do ano, subsidiando a adoção de valores sazonais de vazão máxima outorgável [10-11].

Schneider (2015) [12], ao agrupar todas as estações fluviométricas do Estado em uma única região homogênea, não obteve correlação significativa entre as vazões observada e calculada, com resíduos muito altos, acima de $3000 \%$ em alguns casos. Os elevados valores dos resíduos e baixos valores do coeficiente de correlação [12] foram consequência, principalmente, da diversidade dos regimes dos rios nas regiões climáticas e da baixa densidade de monitoramento em grande parte do Estado, o que dificulta a aplicação da técnica de regionalização de vazões.

O presente trabalho tem como objetivo determinar as equações regionalizadas para $\mathrm{Q}_{90}$ anual e em cada mês, que melhor se ajustam às diferentes regiões climáticas do Estado de Sergipe, ou seja, as equações que resultem em uma pequena variação entre a vazão real, observada na estação fluviométrica, e a vazão calculada pela regionalização.

\section{MATERIAL E MÉTODOS}

Dentre as oito bacias hidrográficas localizadas no Estado de Sergipe, o presente trabalho considerou apenas as bacias dos rios Japaratuba, Sergipe, Vaza Barris, Piauí e Real. As estações fluviométricas instaladas nessas bacias foram agrupadas de acordo com as características climatológicas da região na qual estão situadas.

O clima no Estado de Sergipe é dividido em três regiões distintas, de acordo com temperatura e a precipitação anual: região Tropical Úmida, com a temperatura alta e umidade alta ao longo da costa (Leste); região tropical subúmida ou intermediária mais seca (Agreste), e região semiárida do interior (Semiárido). Na região Tropical Úmida há alta precipitação (média de $1.355 \mathrm{~mm} / \mathrm{ano}$ ), com evaporação acima de $1.000 \mathrm{~mm} / \mathrm{ano}$, porém abaixo das observadas no interior do Estado, e umidade relativa alta (média anual de $80 \%$ ), com média de temperatura em torno de $25^{\circ} \mathrm{C}$. No Agreste, a precipitação é em torno de $1.000 \mathrm{~mm} / \mathrm{ano}$, com evaporação de quase $2.000 \mathrm{~mm} / \mathrm{ano}$, umidade média de aproximadamente $70 \%$ e temperatura média anual de $25^{\circ} \mathrm{C}$. Já a região do Semiárido é consideravelmente mais seca, com precipitação média menor que $700 \mathrm{~mm} / \mathrm{ano}$, com valores inferiores a $30 \mathrm{~mm}$ nos meses de verão, temperatura média anual de $26^{\circ} \mathrm{C}$, evaporação acima de $2.100 \mathrm{~mm} /$ ano e umidade relativa média de $65 \%$ [13].

O regime pluviométrico de Sergipe apresenta uma grande variabilidade espacial e interanual, com secas severas e enchentes em anos diferentes. Os meses secos ocorrem de setembro a fevereiro, sendo outubro o mais seco, e os meses mais chuvosos são maio, junho e julho.

Dentre as estações fluviométricas presentes no estudo, sete localizam-se na região Tropical Úmida - Japaratuba/SE (50040000), Fazenda Cajueiro/SE (50043000), Siriri/SE (50046000), 
Rosário do Catete/SE (50047000), Fazenda Belém/SE (50191000), Estância/SE (50230000) e Itanhy/SE (50290000) -, duas localizam-se na região Agreste - Fazenda Pão de Açúcar/SE (50042000) e Santa Rosa de Lima/SE (50080000) - e quatro no Semiárido - Ponte SE-302/SE (50169000), Fazenda Tourão/SE (50250000), Água Branca/BA (50146000) e Jeremoabo/BA (50150000) -, como mostrado na Figura 1.

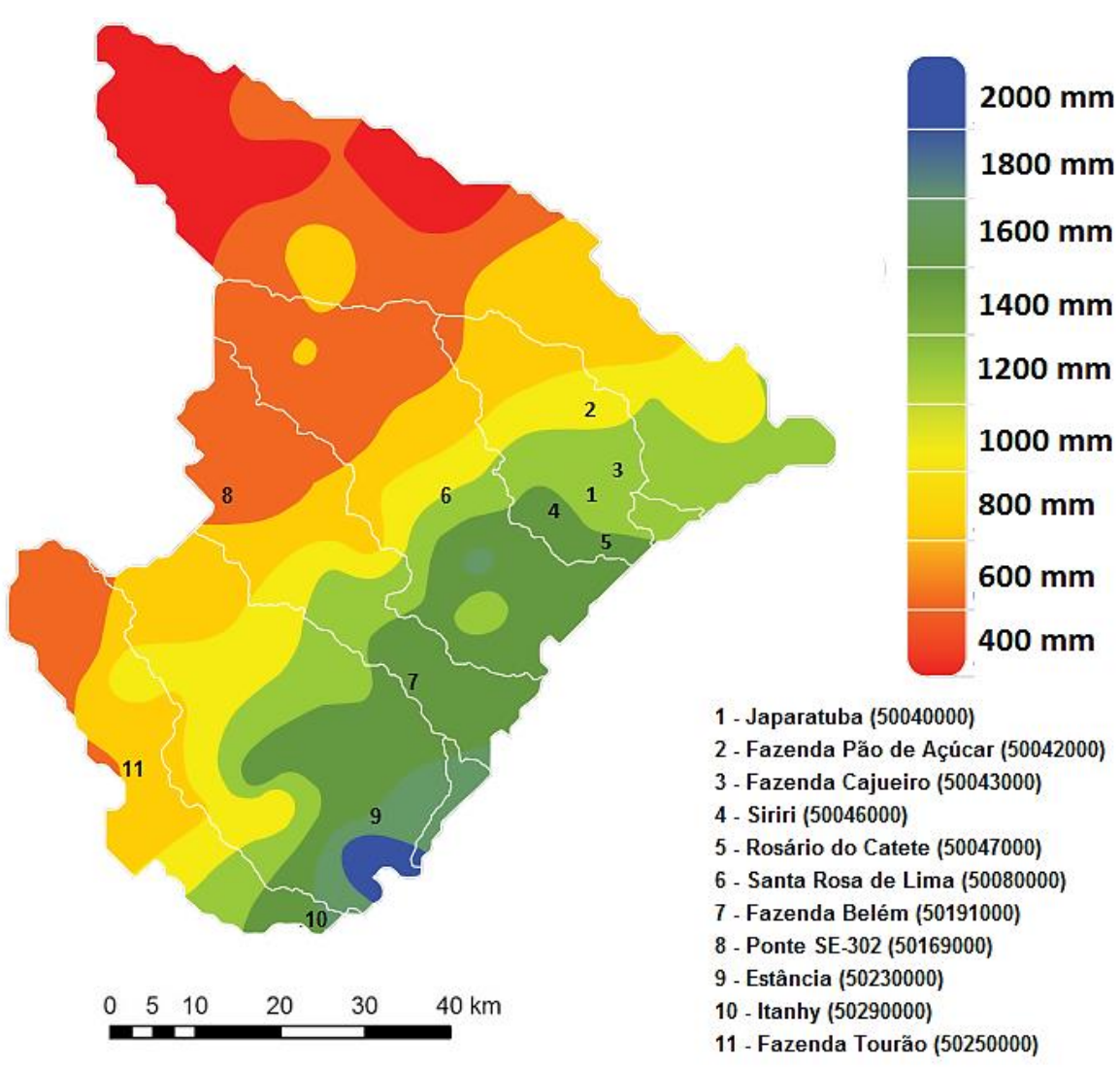

Figura 1: Estações fluviométricas do Estado de Sergipe de acordo com sua precipitação média total. (Fonte: Adaptado de Plano Estadual de Recursos Hídricos de Sergipe: Sumário executivo)

Procedeu-se à regionalização da vazão $\mathrm{Q}_{90}$ considerando a área de drenagem da estação fluviométrica e a precipitação média acumulada como variáveis independentes. Para determinação da área de drenagem das estações, fez-se uso do Atlas Digital sobre Recursos Hídricos de Sergipe [13] e, para as estações situadas no Estado da Bahia, consultou-se a base de dados HidroWeb [14], da Agência Nacional das Águas (ANA). Para os valores de precipitação média acumulada anual e mensal, foram utilizados os dados das estações pluviométricas mais próximas das estações fluviométricas.

Para o processamento das séries históricas de vazão, foi utilizado o software SisCAH, uma ferramenta computacional desenvolvida pelos pesquisadores da Universidade de Viçosa [15]. Para a determinação da curva de permanência, foi considerada a série histórica de vazões no período de 1973 a 1996, e estabeleceu-se um percentual máximo de até 30\% de falhas, tanto para dados anuais quanto mensais. Os dados das estações fluviométricas foram obtidos da base de dados HidroWeb [14].

Para a regionalização da $\mathrm{Q}_{90}$, foi utilizado o software SisCoRV [16]. Empregou-se o Método Tradicional de regionalização, que ajusta os modelos linear, potencial, exponencial, logarítmico e recíproco de regressão à série de dados. Foi estabelecido que a melhor equação de regionalização seria aquela que resultasse em valores mais elevados do coeficiente de determinação $\left(\mathrm{R}^{2}\right)$ e baixos valores de erro padrão e de resíduos. 


\section{RESULTADOS E DISCUSSÃO}

Dentre as diferentes possibilidades de agrupamento das estações fluviométricas segundo a região climática em que estão instaladas, apenas a região homogênea do Litoral, que abrangeu as estações situadas na Região Climatológica Tropical Úmida das bacias hidrográficas do Japaratuba e do Vaza Barris, apresentou bons valores de $\mathrm{R}^{2}$ e resíduos, tanto na regionalização sazonal quanto na anual. A localização dessa região homogênea no Estado de Sergipe é apresentada na Figura 2.

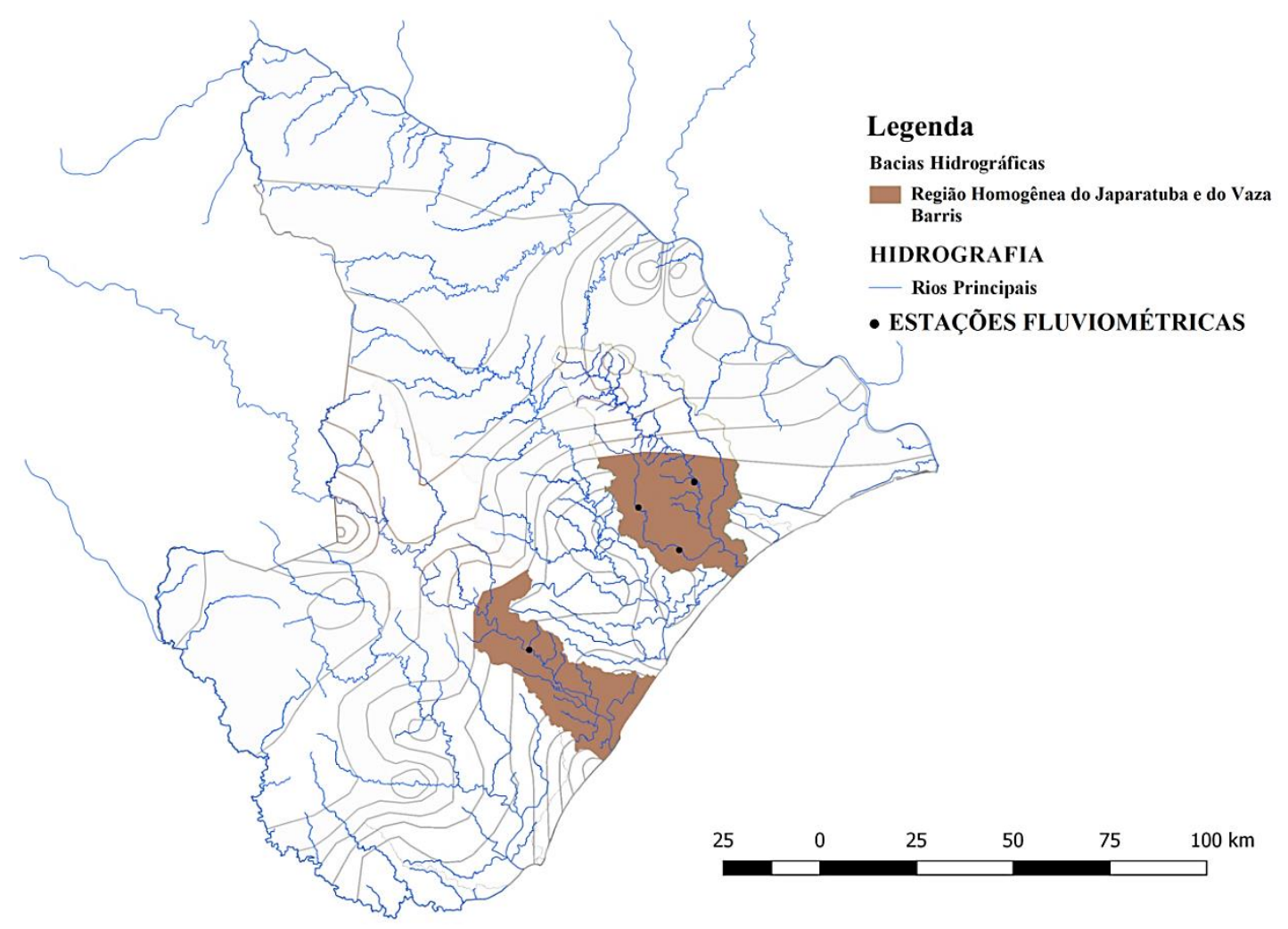

Figura 2: Região Homogênea do Litoral para as bacias Japaratuba e Vaza Barris

As equações de $\mathrm{Q}_{90}$ mensal e anual e respectivos valores de $\mathrm{R}^{2}$ são mostrados na Tabela 1, e os percentuais de resíduo obtidos na regionalização são mostrados na Tabela 2.

Tabela 1: Equações de regionalização para a Região Homogênea do Litoral, $Q_{90}\left(\mathrm{~m}^{3} / \mathrm{s}\right), P(\mathrm{~mm})$ e A $\left(\mathrm{km}^{2}\right)$

\begin{tabular}{clrl}
\hline Estações Fluviométricas & \multicolumn{1}{c}{ Período } & $\mathbf{R}^{2}$ & \multicolumn{1}{c}{ Equação } \\
\hline & Anual & 0,997 & $Q_{90}=6,0690 \cdot 10^{14} \cdot A^{0,4314} \cdot P^{-5,3906}$ \\
& Janeiro & 0,998 & $Q_{90}=11,2727 \cdot A^{0,4462} \cdot P^{-1,9668}$ \\
& Fevereiro & 1,000 & $Q_{90}=\left(18,6874-2,60 \cdot 10^{-4} \cdot \ln A-0,2441 \cdot \ln P\right)^{-1}$ \\
& Março & 0,997 & $Q_{90}=\exp \left(0,0231+1,33 \cdot 10^{-4} \cdot A+0,0249 \cdot P\right)$ \\
& Abril & 1,000 & $Q_{90}=\exp \left(6,5380+1,20 \cdot 10^{-4} \cdot A-0,0237 \cdot P\right)$ \\
Japaratuba & Maio & 0,997 & $Q_{90}=-49,4945+0,4550 \cdot \ln A+9,1203 \cdot \ln P$ \\
Siriri & Junho & 0,988 & $Q_{90}=-16,2876+0,3562 \cdot \ln A+2,9641 \cdot \ln P$ \\
Rosário do Catete & Julho & 0,836 & $Q_{90}=96,7061 \cdot A^{0,3817} \cdot P^{-1,3834}$ \\
Fazenda Belém & Agosto & 0,996 & $Q_{90}=-12,6971-2,23 \cdot 10^{-5} \cdot A+0,1335 \cdot P$ \\
& Setembro & 0,984 & $Q_{90}=9,57 \cdot 10^{10} \cdot A^{0,4301} \cdot P^{-6,5274}$ \\
& Outubro & 0,996 & $Q_{90}=\exp \left(9,71 \cdot 10^{-11}-2,18 \cdot 10^{-4} \cdot A+0,4977 \cdot P\right)$ \\
& Novembro & 0,971 & $Q_{90}=1,2297+0,1286 \cdot \ln A-0,4422 \cdot \ln P$ \\
& Dezembro & 1,000 & $Q_{90}=-0,5130+2,80 \cdot 10^{-5} \cdot A+0,0360 . P$ \\
\hline & & &
\end{tabular}


Tabela 2: Resíduos (\%) para Região Homogênea do Litoral

\begin{tabular}{lcccc}
\hline \multirow{2}{*}{ Período } & \multicolumn{4}{c}{ Estações Fluviométricas } \\
\cline { 2 - 5 } & Japaratuba & \multicolumn{1}{c}{ Siriri } & Rosário do Catete & Fazenda Belém \\
\hline Anual & 0,37 & $-4,57$ & 5,57 & $-1,11$ \\
Janeiro & 1,92 & $-4,94$ & 4,80 & $-1,52$ \\
Fevereiro & 0,07 & $-0,60$ & 0,54 & $-0,05$ \\
Março & $-0,68$ & $-5,82$ & 6,96 & $-0,05$ \\
Abril & 0,72 & $-0,76$ & 0,08 & $-0,03$ \\
Maio & $-1,11$ & $-17,50$ & 13,59 & $-0,44$ \\
Junho & 10,01 & 15,11 & $-16,64$ & $-0,32$ \\
Julho & 16,07 & 35,50 & $-38,61$ & 3,56 \\
Agosto & 5,85 & 8,44 & $-10,19$ & $-0,04$ \\
Setembro & 13,55 & $-0,87$ & $-8,50$ & $-2,91$ \\
Outubro & 0,93 & 3,93 & $-3,92$ & 0,12 \\
Novembro & 4,97 & 9,02 & $-10,46$ & $-0,06$ \\
Dezembro & $-2,06$ & $-0,78$ & 2,95 & 0,02 \\
\hline
\end{tabular}

O pior resultado entre os valores de $\mathrm{R}^{2}(0,836)$ e de resíduos $(-38,61 \%)$ deu-se no mês de julho, o que se justifica em virtude da alta variância da precipitação e, por consequência, das vazões registradas neste mês.

Na Figura 2 observa-se a diferença entre as vazões observadas de cada estação e a vazão calculada resultante do melhor modelo matemático para Região Homogênea do Litoral. Essa discriminação de vazões é importante para o órgão gestor de recursos hídricos do Estado, a fim de que, em caso de solicitação de outorga em algum ponto situado nesta região e que não tenha monitoramento fluviométrico, este possa se basear nos resultados apresentados no estudo.

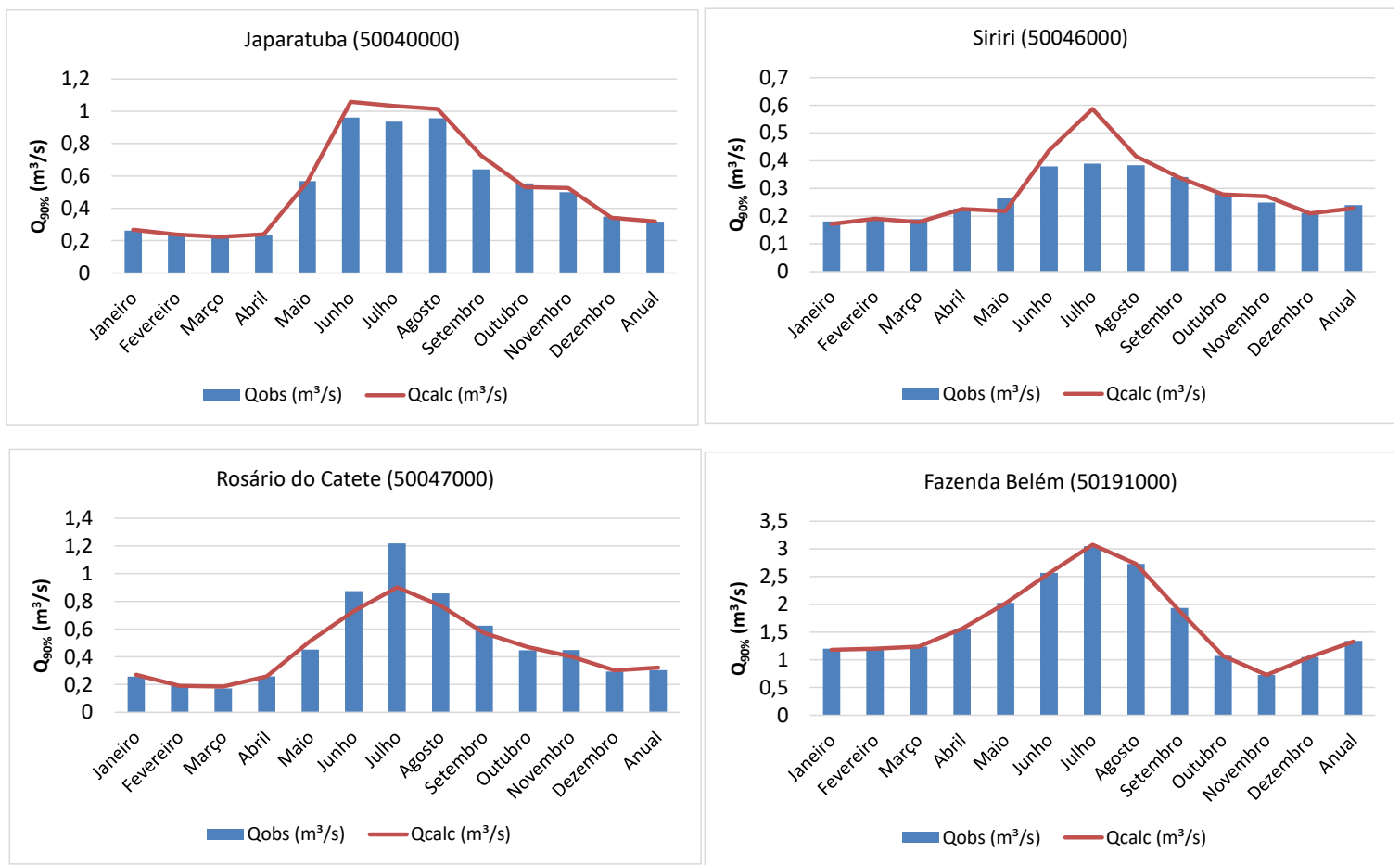

Figura 2: Vazões Observadas e Vazões Calculadas para Região Homogênea do Litoral 


\section{CONCLUSÃO}

Este estudo estabeleceu equações de regionalização da vazão de permanência $\mathbf{Q}_{90}$ para a porção das bacias hidrográficas do Japaratuba e do Vaza Barris situada na Região Climática Tropical Úmida, no Estado de Sergipe. Constatou-se que a baixa densidade de postos fluviométricos em grande parte das bacias sergipanas dificulta a aplicação da técnica de regionalização de vazões, notadamente nas regiões climatológicas do Agreste e do Semiárido.

As equações de regionalização obtidas neste estudo mostraram bom ajuste estatístico às vazões observadas nos postos fluviométricos. O pior desempenho das equações, em relação aos resíduos, foi observado no mês de julho, marcado pelas maiores precipitações e, como consequência, por maior variância de vazões. Não obstante, o coeficiente de correlação em julho ainda foi alto. Os resultados mostraram-se melhores em comparação com estudos anteriores [12], em que a definição das regiões homogêneas baseou-se apenas na delimitação das bacias hidrográficas do Estado. A melhora dos resultados é função, principalmente, da semelhança hidrológica e climatológica entre os rios presentes na região homogênea estudada.

A regionalização sazonal apresentou resultados coerentes com a realidade hidrológica dos rios da região, na qual as chuvas concentram-se de maio a setembro, ocasionando maiores vazões neste período, e com baixo escoamento superficial de outubro a abril, em decorrência de índices pluviométricos menores neste período. Nota-se, assim, uma maior disponibilidade hídrica para outorga no outono e no inverno, confirmando a adequabilidade de se adotar uma vazão máxima outorgável sazonal na região estudada. A sazonalidade da disponibilidade hídrica, se considerada nas análises para concessão da outorga, pode influenciar positivamente a economia regional, na medida em que permite que mais demandas consuntivas sejam outorgadas nos meses úmidos [10]. Tal prática torna mais coerente a aplicação do instrumento da outorga de direito de uso da água e contribui para a eficiência da gestão do recurso hídrico.

\section{AGRADECIMENTOS}

Os autores agradecem o apoio fornecido pela SEMARH.

\section{REFERÊNCIAS BIBLIOGRÁFICAS}

1. Tucci CEM. Regionalização de vazões. Porto Alegre: UFRGS; 2002. 256 p.

2. Alexandre AMB, Martins ESPR. Regionalização de vazões médias de longo período para o Estado do Ceará. Revista Brasileira de Recursos Hídricos. 2005;10(3):93-102, doi:10.21168/rbrh.v10n3.p93-102.

3. Amorim ELC, Oliveira Netto AP, Mario E. Estudo de métodos para regionalização de vazão. In: Anais do 16 Simpósio Brasileiro de Recursos Hídricos; 2005. João Pessoa.

4. Pruski FF, Nunes AA, Rego FS, Souza MF. Extrapolação de equações de regionalização de vazões mínimas: Alternativas para atenuar os riscos. Water Resources and Irrigation Management. 2012;1(1):51-59.

5. Agra SG, Souza VCB, Neves MGFP, Cruz MAS. Metodologias de regionalização de vazões: estudo comparativo na bacia do rio Carreiro-RS. In: Anais do 15 Simpósio Brasileiro de Recursos Hídricos; 2003. Curitiba.

6. Silva Júnior OB, Bueno EO, Tucci CEM, Castro NMR. Extrapolação espacial na regionalização de vazão. Revista Brasileira de Recursos Hídricos. 2003;8(1):21-37, doi:10.21168/rbrh.v8n1.p21-37.

7. Vergara FE, Reis FC, Magalhães LNL. Proposta de vazão de referência Q90 para o Rio Formoso na Bacia do Araguaia. Revista Engenharia Ambiental. 2013;10(1):84-102.

8. Costa VAF, Fernandes W, Naghettini M. Modelos regionais para Curvas de Permanência de vazões de rios perenes, intermitentes e efêmeros, com emprego da distribuição Burr XII estendida. Revista Brasileira de Recursos Hídricos. 2012;17(2):171-180, doi:10.21168/rbrh.v17n2.p171-180.

9. Sergipe. Plano Estadual de Recursos Hídricos de Sergipe: Sumário executivo. Aracaju: SEMARH, 2010.

10. Cruz JC. Disponibilidade hídrica para outorga: avaliação de aspectos técnicos e conceituais [tese de doutorado]. [Porto Alegre]: Instituto de Pesquisas Hidráulicas, Universidade Federal do Rio Grande do Sul; 2001. 
11. Maia JL, Mauad FF, Barbosa AA. Estabelecimento de vazões de outorga na bacia hidrográfica do Alto Sapucaí com a utilização de sazonalidade. In: Anais do 16 Simpósio Brasileiro de Recursos Hídricos; 2005. João Pessoa.

12. Schneider EHM. Regionalização das vazões de permanência no Estado de Sergipe para fins de outorga de uso da água [trabalho de conclusão de curso]. [São Cristóvão]: Universidade Federal de Sergipe; 2015. 92 p.

13. Sergipe. Atlas Digital Sobre Recursos Hídricos de Sergipe: Sistema de Informações sobre Recursos Hídricos de Sergipe. Aracaju: SEMARH, 2016.

14. ANA. Sistemas de informações hidrológicas, HidroWeb. Disponível em: 〈http://hidroweb.ana.gov.br〉 Acesso em 07 mar 2017.

15. Sousa HTS. SisCAH 1.0: Sistema computacional para análises hidrológicas. [Viçosa]: Universidade Federal de Viçosa, 2009.

16. Sousa HT, Pruski FF, Sousa JF, Bof LHN, Cecon PR. Sistema computacional para regionalização de vazões: SisCoRV 1.0. [Viçosa]: Universidade Federal de Viçosa, 2008. 